\title{
Continuous Beer Fermentation Using Immobilized Yeast Cell Bioreactor Systems
}

\author{
Tomáš Brányik, António A. Vicente, Pavel Dostálek, and José A. Teixeira* \\ Centro de Engenharia Biológica, Universidade do Minho, Campus de Gualtar, 4710-057 Braga, Portugal, and \\ Department of Fermentation Chemistry and Bioengineering, Institute of Chemical Technology, Technická 5, \\ 166 28, Prague 6, Czech Republic
}

\begin{abstract}
Traditional beer fermentation and maturation processes use open fermentation and lager tanks. Although these vessels had previously been considered indispensable, during the past decades they were in many breweries replaced by large production units (cylindroconical tanks). These have proved to be successful, both providing operating advantages and ensuring the quality of the final beer. Another promising contemporary technology, namely, continuous beer fermentation using immobilized brewing yeast, by contrast, has found only a limited number of industrial applications. Continuous fermentation systems based on immobilized cell technology, albeit initially successful, were condemned to failure for several reasons. These include engineering problems (excess biomass and problems with $\mathrm{CO}_{2}$ removal, optimization of operating conditions, clogging and channeling of the reactor), unbalanced beer flavor (altered cell physiology, cell aging), and unrealized cost advantages (carrier price, complex and unstable operation). However, recent development in reactor design and understanding of immobilized cell physiology, together with application of novel carrier materials, could provide a new stimulus to both research and application of this promising technology.
\end{abstract}

\begin{tabular}{|lc|}
\hline \multicolumn{2}{|c|}{ Contents } \\
\hline Introduction & 653 \\
Traditional Brewing Process & 654 \\
Economic Incentives of Continuous & 654 \\
Fermentation & \\
Immobilized Brewing Yeast Physiology & 654 \\
Flavor Problems of Beer Produced by & 656 \\
Immobilized Brewing Yeast & \\
Immobilization of Brewing Yeast & 657 \\
Reactor Design and Process Hygiene & 658 \\
Perspectives and Research & 660 \\
\hline
\end{tabular}

\section{Introduction}

Production of ethanol is a technically relatively simple process since the main controlling factors are (specific) productivity and ethanol concentration. In contrast, during beer production the well-balanced aroma and flavor of the final product is equally or even more important than the efficient fermentation and high yield. Naturally, it is not an easy task to reach the desired flavor composed of numerous compounds. The balance of each component forming the beer flavor is very important to beer quality, which is attained by brewers

* To whom correspondence should be addressed. Ph: +351 253 604406. Fax: +351253 678986.E-mail: jateixeira@deb.uminho.pt. through successful combination of old tradition, empirical experiences, and contemporary achievements.

The brewing industry is economically powerful and thus has always been in the forefront of technological development. However, it is prerequisite that any alteration of the technological process must preserve the quality of the final product. Beer is a complex aqueous solution containing $\mathrm{CO}_{2}$, ethanol, inorganic salts and about 800 organic compounds (1). Since in beer brewing the quality of the product cannot be estimated by following a single component such as ethanol, the introduction of a fundamental technological innovation requires an extensive preceding investigation of its influence on the sensorial quality of the product.

The application of immobilized brewing yeasts for continuous beer fermentation is a challenging opportunity for the brewing industry. Nevertheless, pilot-plant and full industrial-scale processes encountered engineering problems (carrier choice, reactor design, risk of contamination) that have, together with the effect of immobilization on yeast physiology, a hardly predictable impact on the flavor profile of the beer produced. Therefore, despite the economic advantages, the continuous process has been so far industrially applied only in beer maturation and alcohol-free beer production $(2-4)$. The objective of this review is to discuss the perspectives of the continuous brewing in regard to the major obstacles posed to the commercialization of this technology and to their potential solutions. 


\section{Traditional Brewing Process}

Although the details of the conventional brewing process are rather variable, depending on the specific type of beer, it always consists of the following four stages: malting, production of wort, fermentation, and beer stabilization together with filtration.

The purpose of malting is to produce enzymes in the barley kernel and to cause defined changes in its chemical constituents. To achieve the desired processes, water is supplied to the interior of the kernel (steeping) and the barley is made to germinate. When the transformations in the green malt have proceeded far enough, kilning is performed in order to terminate the life processes in the kernel and to form color and flavor compounds.

The transformation and dissolution of the insoluble components of the malt into soluble and particularly fermentable sugars is the purpose of wort production. The process consists of three main steps, i.e., mashing (production of extract by the action of enzymes), lautering (filtration or removal of undissolved substances), and wort boiling (extraction of hop components, sterilization, protein precipitation, etc.).

To transform wort into beer, active yeast cells have to be inoculated (pitching) into the cooled and oxygenated wort. The conventional fermentation process consists of two phases, main fermentation and maturation. Typically, 6-7 days are required for the main fermentation, where the conversion of fermentable sugars (glucose, sucrose, maltose, maltotriose) into ethanol and $\mathrm{CO}_{2}$ takes place. Other reactions occurring during main fermentation result in the formation of byproducts (esters, higher alcohols, fatty acids) having a considerable effect on the taste, aroma, and other characteristic properties of the green beer. Nevertheless, some of these yeast metabolism byproducts (vicinal diketones, acetaldehyde, dimethyl sulfide) impart undesirable flavors to green beer. The main aims of maturation (usually 7-30 days) are to reduce the concentration of such unfavorable flavor compounds in the green beer as well as to saturate the final beer with $\mathrm{CO}_{2}$ and to remove the haze-forming components from beer.

The filtration and stabilization of the beer is carried out in order to achieve microbial, colloidal, and flavor stability so that no visible changes occur for a long time and the beer looks and tastes the same as when it was made (5).

\section{Economic Incentives of Continuous Fermentation}

Fermentation and maturation are the most timeconsuming steps in the production of beer. In such a competitive market, the potential time savings offered by continuous fermentation present a challenging dilemma to be addressed. The continuous fermentation process based on immobilized yeast cell technology would allow brewing companies to produce an acceptable end product with great time savings. Thus the main economic advantages of continuous, immobilized cell fermentation are the possibility to use very short fermentation times and to minimize the downtimes (filling, cleaning, standby). Immobilized yeast cell technology allows the production of beer to be accomplished in as little as 2-3 days $(6-11)$.

Nevertheless, time savings (i.e., increase in volumetric productivity) is not a sufficient criterion to dictate a radical transition of the conventional technology. Capital investment, operating costs, and space requirements are among the perspectives of the economic analysis that could justify the continuous beer fermentation technology. The total investment costs for the continuous immobilized process were estimated to be $15-100 \%$ of the batch process $(2,8,12,13)$ depending significantly on the carrier costs and on the technology applied. Thus the use of cheap carrier materials will favor the economics of the immobilized process. When comparing the operating costs of both continuous and batch process a wide range starting from $70 \%$ savings to 1.8 -fold higher values for the continuous process are obtained $(8,12,14)$. Apparently, the running cost estimations largely depend on the annual production of the evaluated breweries, on the applied technology, and on the comprehensiveness of the economic analysis. Smaller floor area requirements of the continuous immobilized process are expected, which also implies savings in the investment (building) costs. Additional savings are generated by reduced beer losses and flexibility of the continuous process (15).

The potential benefits of a continuous fermentation can be diluted by drawbacks imposed through any mismatch with other upstream or downstream processes. Continuous main fermentation and maturation would be much more attractive if the previous stages, e.g. brewhouse, were operated continuously. Although some attempts toward continuous wort production were made (16-18), the production of wort is still a series of batch processes and operations.

\section{Immobilized Brewing Yeast Physiology}

The shorter residence time in continuous fermentation systems leading to increased volumetric productivity is achieved through a controlled contact of fermentable substrates with a high concentration of active biomass. The maximum yeast concentration, e.g., in a packed-bed reactor using immobilized cells, can be up to 10 times greater than at the end of the conventional batch fermentation (19), which is obtained by immobilization of the biomass. Evidence that artificial or natural immobilization of microorganisms provokes different physiological responses when compared to free cell systems have been frequently observed (20). Continuous fermentation with immobilized brewing yeast may induce modifications in cell physiology due to

-continuous mode of reactor operation

-internal and external mass transfer limitations

-specific microenvironment (e.g., created by an immobilization matrix)

-aging of immobilized biomass

Continuous Mode of Reactor Operation. During traditional beer fermentation the yeasts regulate their metabolism with respect to changing internal needs and adjust them to gradually changing external environment, e.g., dissolved oxygen and substrate depletion. Such control is exerted at the level of gene expression, mediated through intracellular metabolite composition and membrane dynamics, and results in sequential uptake of nutrients such as fermentable sugars and wort amino acids (21) and alterations in the activities of different metabolic pathways. On the other hand, the steady-state immobilized cells in a continuous system are not exposed to significant alterations in reaction environment (22). The microbial population of the continuous systems lacks distinct lag, exponential, and stationary growth phases, and this implies a shift from a constantly changing batch to a steady-state continuous operation. The batch fermentation can be mimicked in continuous systems either in tubular reactors with plug-flow (2) or in a series of agitated reactors (8). Therefore, complete continuous beer 
fermentation systems usually consist of two or more fermentation vessels, combining agitated vessels and plug-flow-like packed-bed reactors, where the correct balance of flavor compounds in beer is achieved by controlling the temperature, dissolved oxygen, and other substrate levels in the reactors $(7,14,23,24)$.

Internal and External Mass Transfer Limitations. The external mass transfer is to a large degree determined by reactor design. The transfer of nutrients (oxygen, sugars, amino acids) from the wort through the stagnant liquid film to the carrier surface may affect the concentration of metabolites in the vicinity of the immobilized biomass influencing thus the yeast physiology and consequently the beer flavor (25). The main issue when regarding external mass transfer is the choice between reactor types and their operation regime. This will be discussed in more detail later in this review.

When cells are entrapped, e.g., in a polymer matrix, there may be internal mass transfer limitations of nutrients, the degree of which is also given by the position of the cells, bead size, and type of polymer. These mass transfer limitations constitute the most evident hypothesis to explain the often-observed decrease in immobilized cell growth rate (26) and specific productivities (27) as compared to free-cell cultures. In an aerobic process, the most common option to improve oxygen diffusion in immobilized cell systems is to reduce bead diameter. However, the oxygen gradient in $2 \mathrm{~mm}$ diameter gel beads (9) used for continuous beer fermentation may not be absolutely critical. In fact, gel beads may give rise to an axial oxygen gradient from aerobic (gel surface) to anaerobic (bead center) conditions, simulating thus the yeast metabolism during traditional batch beer fermentation.

It is generally believed that preformed porous (sintered glass) and nonporous surfaces (DEAE-cellulose, wood chips, spent grains) carriers do not have the additional gel diffusion barrier and the direct contact of cells with the bulk liquid does not create significant mass transfer limitations and specific microenvironments. However, depending on the porosity of the carrier and on the amount of biomass adsorbed in the pores, various degrees of internal mass transfer limitations may occur (28). In the case of nonporous carriers, the internal mass transfer problems vary with the thickness of the cell layers (biofilm). Free and immobilized cells adhered in a single layer to DEAE-cellulose showed similar metabolic activities (24), whereas the multilayers biofilm yeast attached to spent grains had significantly lower specific saccharide consumption rate than free cells $(29)$.

Specific Microenvironment (e.g., Created by an Immobilization Matrix). Another factor influencing the cellular activity of immobilized cells is the microenvironment inside and around the solid immobilization matrix. Therefore, when judging the metabolic activity of immobilized cells, parameters such as water activity, $\mathrm{pH}$, oxygen, temperature, substrate and product concentration gradients have to be regarded as well (30). However, since the information concerning physiological conditions of immobilized yeast is rather complex due to different matrices and variable system configurations, it is difficult to compare different experiments.

Activation of some metabolic functions (substrate uptake, product formation, enzyme expression and activity) of immobilized cells has been reported (31-34). According to some authors, the enhanced metabolic activity can be attributed also to surface sensing responses in immobilized microbial cells (35), but the reasons are still a matter of controversy. Overall, conclu-

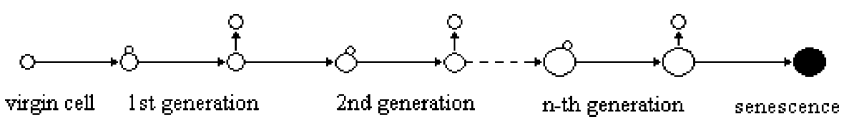

Figure 1. The progression from a virgin cell (daughter cell) to senescence.

sions should be very carefully drawn from the results, since sampling and sample treatment may also influence the immobilized cell physiology measurements. For example, the yeast sample released from a stainless steel fiber cloth immobilization matrix had a reduced activity of glucose utilization, measured by the acidification power test, while the whole immobilized system exhibited a fermentation activity superior to that of the free-cell system (36). This suggests the loss of glucose utilization activity during the cell sample preparation compared to immobilized cells in situ.

Many reports underline also the increased ethanol tolerance of the immobilized cells $(37,38)$. Being an important parameter in the performance of alcoholic fermentation, the increased ethanol tolerance of immobilized brewing yeast is particularly interesting for both traditional and continuous high gravity wort fermentation (39). The increased resistance to inhibiting substances is connected either to changes in the composition and organization of the cell wall and plasma membrane of the immobilized cells (40) and/or to some protective effect of the immobilization support (41).

It has been shown that immobilized cells exhibit increased levels of DNA, structural carbohydrates (42), glycogen (26), and fatty acids (32), as well as modifications of cell proteome, cell wall and cell membrane composition (43-45). Not surprisingly, the alterations of plasma membrane composition have a profound impact on several enzymes, sensor proteins, transporters and membrane fluidity. Hence, changes of plasma membrane induced by immobilization may play a crucial role in the alteration of sugar and amino acids transport and uptake in immobilized brewing yeast $(36,45,46)$.

Aging of Immobilized Brewing Yeast. The yeast Saccharomyces cerevisiae has a limited replicative lifespan. Each cell is only capable of a finite number of divisions, usually within the range of 10-30 divisions, before entering a nonreplicative state termed senescence (Figure 1), leading to death and autolysis (47). As a consequence of aging and senescence, the polyploid brewing yeast cells are subject to modifications in terms of physiology, morphology and gene expression. Such modifications include decrease of viability (48), increase in size, wrinkling of the cell surface, increase of generation time, increasing bud scar number and decrease in metabolic activity $(49,50)$. Chronological lifespan has been defined as the long-term survival of cells maintained in stationary phase (51).

The study of the aging process of brewing yeast strains has also a practical significance. The aged brewing yeasts show changed flocculation characteristics (52) and fermentation performance $(53,54)$. It is believed that the performance of lager strain begins to degenerate after 10 serial repitchings (55). When comparing the maximum age that brewing yeast can reach in traditional technology with the long periods of time that immobilized cells are spending in a continuous reactor, e.g., primary beer fermentation operating for several months $(14,10)$, the question of the immobilized cell age and physiology turns to be even more relevant. Although the viability and fermentation capacity (vitality) of immobilized brewing yeast in continuous fermentation systems have already been reported to decrease $(8,56-58)$, there is little known 
on the senescence and aging process of immobilized yeast in continuous beer fermentation systems and on their impact on product quality. Hence, elucidating the influence of different immobilization methods on aging of brewing yeast and understanding the effect of senescence on cell vitality and fermentation performance would be of a great practical importance. As a consequence, proper measures to increase the operational lifetime and fermentation performance of the bioreactor could be taken. Nevertheless, it can be anticipated that yeast strains with low Hayflick limit (maximum lifespan potential) would not be appropriate for continuous fermentations or immobilized systems.

\section{Flavor Problems of Beer Produced by Immobilized Brewing Yeast}

Beer flavor is the result of a complex combination of components, resulting both from the raw materials and from the yeast metabolism. Poor amino acid uptake, low formation of esters and higher alcohols and high production of vicinal diketones by immobilized brewing yeast have been frequently reported $(7,59)$. On the other hand, immobilized cell growth positively influenced the formation of flavor-active compounds similarly to traditional batch fermentation (60). Taken together, the differences in growth metabolic state between free and immobilized cells are most probably responsible for most of the alterations in the flavor of beers produced in immobilized systems.

Diacetyl is the most flavor-active vicinal diketone formed as a byproduct during primary (main) fermentation. It has a very low taste threshold of approximately $0.15 \mathrm{mg} / \mathrm{L}(61)$ and is responsible for an unclean, sweetish taste in beer, which turns into a buttery off-flavor if in higher concentrations (5). The formation of diacetyl results from the chemical oxidative decarboxylation of excess $\alpha$-acetolactate leaked from the isoleucine-valine biosynthetic pathway to the extracellular environment. Since $\alpha$-acetolactate, the precursor of diacetyl, is an intermediate of valine synthesis, diacetyl is formed when yeast synthesize valine (62). Unfortunately brewer's yeast does not possess $\alpha$-acetolactate decarboxylase, an enzyme produced by several bacterial species, which converts $\alpha$-acetolactate into acetoin, a significantly less flavoractive compound. Therefore in traditional brewing technology $\alpha$-acetolactate is reassimilated by the yeast as diacetyl, which is then reduced enzymatically to acetoin and further to 2,3-butanediol during the time-consuming maturation (63).

Primary beer fermentations with immobilized cells often report the production of excessive amounts of diacetyl. The extensive production of $\alpha$-acetolactate and subsequently diacetyl in continuous immobilized cell systems can be interpreted as:

-A consequence of the shortened fermentation time disabling the sufficient decay and reassimilation of these compounds in beer. It is also supported by the fact that increasing the concentration of immobilized cells at the same residence time leads to lower diacetyl concentration in beer (64).

-A result of the accelerated expression of the acetohydroxy acid synthetase responsible for the formation of $\alpha$-acetolactate (precursor of diacetyl) from pyruvic acid (33) due to immobilization.

-An alteration of the amino acid metabolism of the immobilized cells. It is influenced by both enhanced anabolic formation of amino acid precursors due to rapid yeast growth and by an unbalanced feed back inhibition of the isoleucine-valine biosynthetic pathway. Neverthe- less, the data on amino acid uptake by immobilized cells are often contradictory and influenced by the applied immobilization technique. Lower amino acid uptake by entrapped yeast has been frequently reported $(8,59)$, while immobilization by attachment showed uptake rates similar to free cells $(24,36,56)$.

At the end of the maturation process (secondary fermentation), all $\alpha$-acetolactate in the green beer should be converted into diacetyl and further reduced by yeast cells into acetoin and butanediol. Otherwise, diacetyl formed chemically from $\alpha$-acetolactate after filtration will remain in the final product, deteriorating its quality. Several strategies have been developed in order to speed up the maturation of green beer produced either by continuous immobilized or traditional batch technology:

-Addition of the missing enzyme, bacterial $\alpha$-acetolactate decarboxylase, to the fermenting beer converting $\alpha$-acetolactate directly to acetoin. Bacillus enzymes have shown to be the most stable under the conditions of the fermentation (65).

-The use of genetically modified brewer's yeast encoding $\alpha$-acetolactate decarboxylase can significantly shorten the beer maturation (lagering period) or even make it unnecessary $(66,67)$.

-Amplification of the genes in ILV (isoleucine-valine) pathway. Insertion of multicopy plasmids encoding a reducto-isomerase, an enzyme catalyzing a rate-limiting step in the conversion of vicinal diketone precursors to isoleucine and valine, resulted in a 50-60\% reduction of vicinal diketones production compared with the control yeast (68).

- Heat treatment for $10 \mathrm{~min}$ at $90^{\circ} \mathrm{C}$ between primary and secondary fermentation is sufficient to convert all available $\alpha$-acetolactate to diacetyl and partly to acetoin. The diacetyl is then reduced to acetoin during maturation with continuous immobilized yeast system operating at a residence time of $2 \mathrm{~h}$. Nevertheless, to avoid formation of off-flavors, yeast must be removed from the green beer and oxygen pick up must be prevented $(6,69,70)$.

-Continuous beer fermentation with immobilized genetically modified yeast not requiring a time-demanding maturation step is a realistic possibility. The total fermentation time would be about 1-2 days without affecting the flavor of the final beer (71). However, as long as there remain both legal obstacles and the consumers' negative attitude toward the use of genetically modified yeast, it is possible to combine the heat treatment of green beer with conventional immobilized brewer's yeast in continuous maturation systems.

The oxygen supply in primary fermentation is critical for adequate beer flavor formation. Insufficient aeration leads to decreased yeast viability, low amino acid uptake due to suppressed cell growth, and suboptimal lipid synthesis giving rise to altered membrane composition and thus to fermentation problems and unbalanced flavor profile (72). On the other hand, excess oxygen leads to production of unnecessary yeast biomass, low ester production, but excessive acetaldehyde, diacetyl, and fusel alcohol formation $(29,73)$. The latter was explained by the intense yeast growth resulting in either enhanced wort amino acid catabolism and/or amino acid biosynthesis accompanied by overproduction of higher alcohols, oxo-acids, organic acids, and vicinal diketones $(28,74)$. Simultaneously, higher temperatures were reported to increase the amount of $\alpha$-acetolactate (75), fusel alcohols, esters, and acetaldehyde in beer (24) by influencing the rate of yeast growth. The same positive effect on higher alcohol and ester production has been provoked by the immobilization-induced acceleration of cell metabolism (36). 
Table 1. Examples of Carrier Types Used for Beer Fermentation by Immobilized Brewing Yeast

\begin{tabular}{ll}
\hline \multicolumn{1}{c}{ carrier material } & \multicolumn{1}{c}{ references } \\
\hline Ca-alginate & $3,9,77,131$ \\
$\kappa$-carrageenan & $9,24,57,124$ \\
wooden chips & 45,82 \\
diatomaceous earth & 81,98 \\
DEAE cellulose & $2,6,56,66,81$ \\
porous glass (Siran) & $10,14,23,66,81,82$ \\
silicon carbide & $7,10,129$ \\
gluten pellets & 130 \\
spent grains & 11,29
\end{tabular}

An optimum oxygen supply is also important for adequate ester formation since the excess of aeration inhibited the cytosolic alcohol acetyl transferase, responsible for ester formation in yeast (72). Conversely, anaerobic conditions and the absence of unsaturated fatty acids in wort limit cell growth and stimulate formation of acetate esters (76). Another mechanism of ester overproduction was presented for brewing yeast attached to stainless steel fiber cloth. It was hypothesized that because of the lower fatty acids synthesis by immobilized cells, the accumulation of acyl-CoA (unconsumed for fatty acids anabolism) together with high levels of fusel alcohols led to enhanced formation of esters (36). However, it is difficult to distinguish whether the lower fatty acid biosynthesis is a result of immobilization-induced changes of the plasma membrane or a consequence of reduced cellular growth caused by oxygen limitation inside the carrier matrix (77).

Besides the formation of desirable compounds, different alcohol dehydrogenase systems of brewing yeast are involved in the reduction of wort carbonyl compounds, known to impact negatively on beer flavor. The reduction of wort aldehydes, together with low ethanol and diacetyl production, is the crucial process in alcohol-free beer production. Concerning the influence of immobilization on different yeast enzymatic mechanisms involved in carbonyl reduction, it was found that either they were not affected (78) or the reducing capacity of yeast was improved (34). The increased alcohol dehydrogenase activity in immobilized yeast was found to be correlated with immobilization-induced (DEAE-cellulose) higher glucose flux in cells. Since the enzymatic reduction of aldehydes by $S$. cerevisiae is coupled to the oxidation of cofactors $\mathrm{NADH}$ and NADPH, the higher aldehyde reduction capacity can be ascribed to the efficient cofactor regeneration during faster glycolysis and pentose phosphate pathway (34).

The optimization of aeration and fermentation temperature seems to be an important tool for the control of flavor-active compound formation in continuous immobilized beer fermentation systems. It is possible to adjust the flavor of the continuously produced beer to the desired character by sparging an adequate amount of air, eventually in mixture with nitrogen or carbon dioxide as an inert gas, and by controlling the fermentation temperature in the immobilized yeast reactor $(29,66,79,80)$. Nevertheless, the effect of air feed on the flavor and aroma compounds is complicated by the problem of mass transfer capabilities of the reactor, mass transfer limitations of the applied carrier (72) and the carrier material itself (81).

\section{Immobilization of Brewing Yeast}

Various carrier types have been used for beer fermentation by immobilized brewing yeast so far (Table 1.). When considering the implementation of the most suitable support matrix for continuous beer fermentation with immobilized brewing yeast, the following aspects should be taken into account:

-properties of the carrier material (price, stability, rigidity, inertness, regeneration, approval for food use, scale-up potential)

-mechanism of immobilization (type, ease, cell loading, modifications of microbial metabolism)

-reactor configuration (reactor type, mass transfer limitations, reactor mixing characteristics, clogging)

Inert carrier types used recently for immobilization by attachment and adsorption have shown to be technically useful and economically affordable. Therefore, they have been receiving more attention than the polysaccharide gel entrapment matrices. It was also found that the cellulose-based carrier materials were regenerable, reusable, heat sterilizable, biologically and chemically stable under fermentation conditions, neutral in taste, foodapproved and mechanically sufficiently stable $(82,83)$. Similarly, advantageous material characteristics can be summarized for porous glass carriers also (84). However, in terms of carrier costs, the price of carriers such as wood chips and spent grains is especially advantageous, since they are byproducts of the woodworking and brewing industries, and apart from smoked food manufacturing and animal feed, respectively, they have a limited application. Moreover, the preparation of wood chips and spent grains from their raw materials is a simple process performable directly in breweries $(82,83)$. The principles of cell immobilization onto preformed porous and nonporous carriers involve different mechanism such as:

-adsorption within a carrier cavity (mechanical retention and colony formation in protected macropores)

-microbial self-aggregation (cell-cell attachment, flocculation, chain formation)

-immobilization by adhesion to solid surfaces (covalent, electrostatic, ionic, hydrogen bonding, hydrophobic forces and biochemical interactions between cells and support)

Most of the supports combine various mechanisms; however, in some cases a prevailing principle can be found. For example, nonmodified porous glass (Siran) displays predominantly immobilization by adsorption (85), whereas DEAE-cellulose uses ionic attraction between its positively charged surface and cells with net negative surface charge. This charge difference may be strongly reduced as a result of the adsorption of wort components (86). Spent grain particles, on the contrary, besides mechanical retention in pores and cavities, are assumed to take also advantage of hydrophobic surface properties leading to a stable cell-carrier adhesion (Figure 2). Moreover, mechanisms such as flocculation or chain formation may play a role in multilayer yeast immobilization on solid nonporous spent grain carrier particles (87).

Independently of the specific mechanism, the attachment/adsorption is the most gentle immobilization method resulting in a mono- or multilayer yeast biofilm attached to the external and/or internal surface of the carrier matrix in direct contact with the surrounding environment. As a consequence of the lack of an additional diffusion barrier between the cells and the bulk medium, mass transfer can be considered less limiting and dependent only on the thickness of the biofilm. The main drawback of the attachment to a surface, especially if such surface is directly exposed to the external medium, is the relatively weak cell to carrier bond and thus the sensitivity of the biofilm to changes in the surrounding environment. Alterations of the medium composition (ionic strength, $\mathrm{pH}$, substrate), temperature and mechanical stress may induce cell desorption and detachment (25). Hence, if cell-free effluents are required in order to 


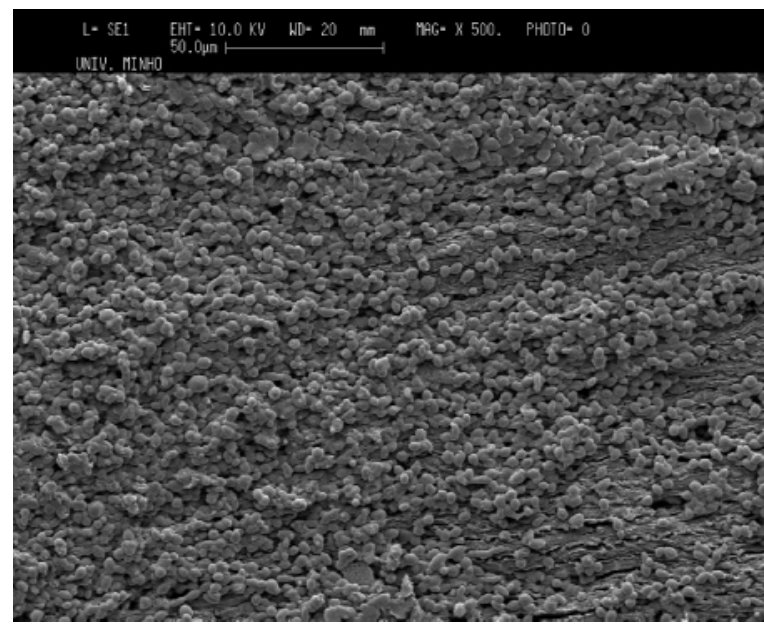

Figure 2. Photomicrograph (SEM) of a spent grain particle surface with adhered brewing yeast cells.

make savings on filtration, other immobilization techniques should be preferred when considering the options for a continuous immobilized cell fermentation system. Nevertheless, the disadvantage of the biofilm detachment from the point of view of shear stress sensitivity and more demanding downstream processing can turn to a plus when biofilm regeneration is required, e.g., when aging of the immobilized brewing yeast over long-term beer fermentation impairs the yeast quality. In the case of spent grains carrier, biofilm regeneration can be regularly carried out by biofilm detachment (by mechanically or pneumatically generated shear stress) followed by recolonization of the carrier $(11,29,88)$.

Entrapment of cells within polymeric matrices is one of the most widely used techniques for yeast immobilization research. Compounds such as agar, alginate, chitosan, gelatin, $\kappa$-carrageenan, polyacrylamide and poly(vinyl alcohol) are nontoxic polymeric materials used to form gel supports around the cells (89). The most common form of gel beads is spherical with diameters ranging from 0.3 to $3 \mathrm{~mm}$, although the smaller diameter beads are usually preferred because of the more favorable mass transfer characteristics. These techniques are easy to perform on a laboratory scale and characteristically allow a considerably higher biomass load than immobilization onto preformed supports. However, their possible application in large-scale continuous beer production, especially primary fermentation, is rather complicated. Bead fracture due to $\mathrm{CO}_{2}$ buildup, cellular growth, and abrasion in fluidized bed and compression in packed bed reactors with subsequent loss of matrix integrity are central problems of most gel-entrapped systems $(8,90)$. Although the stability of gel beads can be increased by, e.g., coating the gel or using hardening agents, the toxicity of reagents, their higher price and the impossibility of regeneration cause that gel matrices are scarcely applicable in industrial scale continuous immobilized beer fermentations (91). Another concern as regards gel entrapment is the metabolite concentration gradient caused by diffusion limitations. In a biomassloaded gel matrix, the availability of substrate or inhibitory products differ at the gel surface and in the bead center, which may affect both cell physiology (causing cell starvation or dead) and the formation of flavor components (92).

Brewing yeast possesses the natural ability to aggregate (flocculate), and this phenomenon can be exploited as the cheapest immobilization method (93). Although early studies of continuous beer fermentation systems taking advantage of the self-aggregation of
Table 2. Reactor Types Used for Continuous Immobilized Cell Beer Fermentation

\begin{tabular}{lll}
\hline reactor type & \multicolumn{1}{c}{ process } & \multicolumn{1}{c}{ references } \\
\hline packed-bed & primary fermentation & $14,56,66$ \\
packed-bed & secondary fermentation & $2,6,9,130$ \\
gas lift & primary fermentation & $9,11,24,29,124,130$ \\
fluidized bed & primary fermentation & 10,131 \\
loop reactors & primary fermentation & $7,10,129$
\end{tabular}

brewing yeast pointed out the low predictability of the cell flocculation mechanism (94), such a system has been running at a commercial scale for decades at DB Breweries Ltd. of New Zealand (95). Promising attempts have also been made to implement this immobilization strategy to continuous beer maturation (96). However, because self-aggregation is affected by numerous parameters such as nutrient conditions, yeast strain, dissolved oxygen, $\mathrm{pH}$, fermentation temperature, and yeast handling and storage conditions, it has not found wider application (97).

\section{Reactor Design and Process Hygiene}

Reactor design and immobilization matrix rank equally in defining catalytic efficiency and volumetric productivity. For each type of immobilized cell system a variety of reactor types can be selected, and optimal performance requires a careful matching of immobilization method, reactor configuration and process characteristics. Although immobilized brewing yeast can be employed in various types of reactor (Table 2), when evaluating these for continuous beer fermentation with immobilized cells, a clear difference has to be made between the processes of the primary and secondary fermentation.

Primary fermentation is a biochemically rather complex process accompanied by intense biomass growth and carbon dioxide evolution. This imposes significant technical demands on the immobilized cell reactor design, such as homogeneous solid-phase distribution, sufficient mass and heat transfer, removal of excess yeast and $\mathrm{CO}_{2}$, prevention of clogging and channeling, creation of dead volumes in the reactor. Consequently, mixing is a crucial parameter in immobilized cell system design for primary fermentation and therefore mixed particle reactors possess some advantages over packed bed reactors.

Agitated reactors allow the use of small size carrier particles (11) that would cause serious channeling and clogging problems in stationary particle reactors (98). Stirred tanks, however, are not suitable for mechanically less resistant immobilized cell systems because of high local shear stress caused by propellers. This renders the pneumatically agitated bioreactors to be the most appropriate for such systems. Generally speaking, low shear, optimal liquid mixing, good heat and mass transfer, and reduced risk of contamination and mechanical failure characterize both fluidized bed and gas lift devices, with the later using even less power than fluidized bed reactors. Besides, the fluidized bed system is not an ideal choice when the immobilization matrix provides particles with low density. In this case, the fluidized bed reactor can work only at very low air/liquid flow rates, to prevent solid-phase washout, resulting in low mass transfer rates $(12,72)$.

Despite of the relative functional simplicity of the internal loop gas lift reactors (Figure 3), a wise consideration of the geometric design and fluid dynamics of the gas/liquid/solid system may improve significantly the volumetric productivity and operational stability of such reactor when used as part of a continuous immobilized cell system. Since the continuous primary beer fermentation does not require a large oxygen supply once excess aeration causes product deterioration, the gas-liquid 


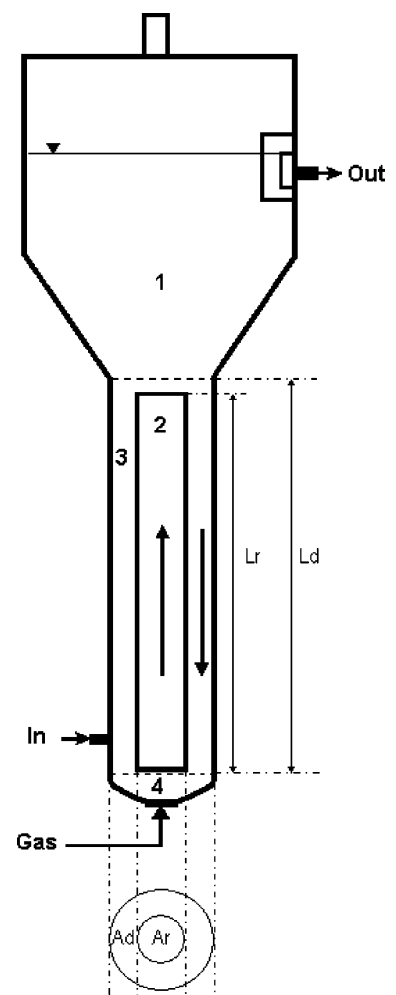

Figure 3. Schematic diagram of a concentric tube gas lift reactor. The reactor is divided into sections: (1) gas-liquid separator; (2) riser; (3) downcomer; and (4) bottom clearance. Further abbreviations: Lr, riser length; Ld, downcomer length; $\mathrm{Ar}$, riser cross-sectional area; Ad, downcomer cross-sectional area.

mass transfer coefficient $\left(k_{\mathrm{L}} \mathrm{a}\right)$ for oxygen is not a crucial parameter of the process. It is rather the stalling due to increasing solid load and/or low gas flow $(29,99)$ that is a matter of concern when using a three-phase gas lift reactor for primary beer fermentation. Another weak point of a three-phase system with immobilized cells, especially when the biocatalyst consists of biomass attached to a solid nonporous carrier (e.g., brewing yeast on spent grain particles), may be the shear-stress-induced biofilm detachment or abrasion $(11,29)$. In other words, under normal circumstances the objective is to run the gas lift reactor reliably with high solid (biocatalyst) load and at the same time at a reasonably low shear rate and with low mass transfer resistance. However, the increased shear rate inside the reactor might have also a practical significance when the goal is to liberate the excess or aged immobilized biomass. This can be achieved by understanding the hydrodynamic behavior of the three-phase system, which is determined by parameters such as gas hold-up, gas-liquid interfacial area, volumetric phase distribution, liquid mixing time, liquid circulation velocity, liquid- and gas-phase axial dispersion, fluid-wall heat transfer, and cell retention capacity (100). All of the above-mentioned parameters are, in turn, influenced by the reactor design and operation variables of the specific process:

-Sparger design. The location of the gas sparger in the bottom of the riser improved the hydrodynamic performance rather than the downcomer ring sparger (101).

-Riser and downcomer dimensions. The riser to downcomer cross-sectional area $\left(A_{\mathrm{r}} / A_{\mathrm{d}}\right)$ and length $\left(L_{\mathrm{r}} / L_{\mathrm{d}}\right)$ ratio have a very important influence in the performance of the reactor. Both the increase of $A_{\mathrm{r}} / A_{\mathrm{d}}$ and $L_{\mathrm{r}} / L_{\mathrm{d}}$ ratio were found to increase the liquid velocity $(102,103)$, positively influencing the maximum solid hold-up the reactor can deal with. In high cell density systems a uniform solid distribution was achieved at an $A_{\mathrm{r}} / A_{\mathrm{d}}$ ratio around $0.5-0.8$ (104)

-Gas-liquid separator. It is situated at the top of an airlift reactor where riser and downcomer are connected and has a major influence on the entire behavior of the reactor: gas recirculation rate, mixing time, liquid velocity, gas hold-up in the downcomer, $k_{\mathrm{L}}$ a, and retention of solid phase (biocatalyst) in the bioreactor (105-107).

-Bottom clearance. The distance from the reactor base to the riser tube (bottom clearance) was found to have a major influence on the dynamic pressure drop and formation of dead zones near the bottom responsible for sedimentation of solids $(108,109)$.

-Solids load. Increasing solids loading provoked a decrease in liquid circulation velocity and an increase in critical air flow rate and mixing time $(102,110,111)$.

-Gas input. Circulation and mixing times decreased with the increase of airflow rate $(111,112)$.

-Solid and liquid phases. A small increase in solids specific gravity (values close to that of water) increased significantly the critical airflow rate and mixing time in solid-water-air systems. The reduction of surface tension with the addition of ethanol increased the riser and downcomer gas hold-up, leading to a decrease of the solids hold-up in these sections. $(102,113)$.

-Design modifications. A static mixer is a device that changes significantly the fluid dynamics in the gas lift reactor and consists of a series of static baffles (e.g., helical flow promoter). The following effects of the static mixers have been described: enhanced capacity for fluidizing solid particles, decrease of critical gas flow rate, increased mass transfer rate, decreased circulation time, and increased shear stress (114-116).

The main target of secondary fermentation (beer maturation) is to balance the final beer flavor, mainly by reducing diacetyl and other carbonyl compounds. Although the process does not require aeration, carbon dioxide as a gaseous end product must be removed turning the system into a three-phase reactor. Otherwise, the system has to be operated under pressure in order to maintain the carbon dioxide in solution. During maturation the beer reaches also the final attenuation, which is accompanied by a moderate cell growth comparing to primary fermentation $(4,117)$. Although in primary fermentation the bioreactor became seriously clogged with a combination of DEAE-cellulose carrier and growing yeast, the same carrier has been successfully used for industrial beer maturation in a packed-bed reactor (82). Thus, the secondary fermentation represents, from an engineering point of view, a less complicated process allowing the application of stationary particle reactors where the medium is passed either upward or downward through the bioreactor, which is packed with biocatalyst.

The advantages of packed-bed reactors include simplicity of design and operation, low energy requirements and possibility of maintaining a fairly ideal plug flow. The operation of packed-bed reactors in beer maturation represents risks such as uneven nutrient distribution in the bed due to the lack of mixing and channeling and clogging followed by excessive pressure drop caused either by small carrier particle size, material compression or cell growth $(25,93,98)$. Though problems with clogging and channeling were reported when packed-bed reactors were operating in up-flow mode, they can be prevented both by down-flow configuration (2) and by using a noncompressible carrier material or by the addition of porous particles (glass rings) to increase the void volume of the fixed bed (56). 
One of the main obstacles to the acceptance of commercial scale continuous beer fermentation by brewers is the fear for contamination. The continuous immobilized systems are considered by some authors more sensitive to contamination than traditional brewing systems (118), the greatest risk being the number of separate batches of wort that must be collected as feedstock to a bioreactor (119). Others report that even a fast growing contamination in wort supply need not necessarily terminate bioreactor operation when washed-out in time at short residence times (120). Nevertheless, an effective process hygiene, simple equipment design and thorough production control are essential to keep the competitiveness of continuous systems. Factors affecting the microbiological stability of continuous immobilized cell beer fermentation systems are sterile processing, purity of yeast culture at start-up, concentration and growth rate of brewing yeast, fermentation temperature and residence time in the reactor. The growth rate of contaminants at low temperatures and their ability to adhere to brewing yeasts, carrier and reactor surface is also of great importance as regards their maintenance in the bioreactor $(120,121)$. Wort bacteria (Pantoea agglomerans, Obescumbacterium proteus) with high specific growth rate and high dimethyl sulfide production rate were found to be the most hazardous ones during continuous primary fermentation, whereas wild yeast caused both superattenuation and formation of phenolic off-flavors (122). Despite the fact that the industrial bioreactors for sterile processing are designed as pressure vessels capable of sterilization with saturated steam, the vessel should be designed in order to facilitate even more cleaning and sterilization. Accordingly, such vessels should have a minimum number of ports, nozzles, connections, mechanically moving parts, and stagnant areas and should drain fully. The surface finish of the reactor interior also affects the risk of microbial adhesion with implication on the ability to clean, sanitize and sterilize the bioreactor (123).

\section{Perspectives and Research}

Nowadays, the traditional batch process still overwhelmingly prevails over continuous fermentation technology. Predictions that continuous beer fermentation using immobilized cells will outperform existing mainstream brewing technology have not yet become truth. Only a limited number of continuous beer fermentation $(23,124,125)$, continuous maturation $(69,84)$, and alcohol-free beer production $(126,127)$ processes have found industrial application. The cautious attitude of the brewing industry toward continuous beer fermentation, especially primary fermentation, is mainly caused by technical difficulties often encountered during the process and flavor problems with the finished product (128). Although the volumetric productivity of the traditional batch fermentation is lower than that of the continuous process, it can be increased by high gravity wort brewing as well as it appears attractive in terms of operational simplicity. Besides, it is obvious that no existing brewery can simply convert its batch system to a new continuous system, even if such conversion is associated with positive economic advantages. These drawbacks of the continuous fermentation systems are usually enhanced by the disbelief of the brewers based on their lifelong experience with the batch technology.

To convince the brewing engineers and economists that continuous brewing can produce both quality and savings, the researchers should not lose sight of the applicability, simplicity and economic attractiveness of the suggested fermentation systems. The main goal of the current research on continuous beer fermentation using immobilized cell systems, especially when concerning beer quality, is to mimic the changing physiological state of the brewing yeast during traditional fermentation stages in the continuous systems. This should be achieved by means such as tailoring the immobilization matrix and reactor system to the requirements of each fermentation stage and understanding the immobilized yeast aging together with its consequences on sensorial quality of beer. Simultaneously, the investment costs (e.g., carrier price) and unit operations of the future industrial process for continuous beer fermentation should be designed to be as cheap and simple as possible because only these merits can balance the drawbacks of more complex process control and regulation of the continuous system. Unquestionably, the attractiveness of the continuous beer fermentation process would also benefit from a breakthrough in continuous wort manufacturing research.

\section{Acknowledgment}

Financial support from FCT (SFRH/BPD/3541/2000, Portugal) and MSMT (MSM6046137305, Czech Republic) is gratefully acknowledged.

\section{References and Notes}

(1) Hardwick, W. A. The Properties of Beer. In Handbook of Brewing; Hardwick, W. A., Eds.; Marcel Dekker: New York, 1995; pp 551-585.

(2) Pajunen, E.; Grönqvist, A.; Lommi, H. Continuous Secondary Fermentation and Maturation of Beer in an Immobilized Yeast Reactor. Tech. Q.-Master Brew. Assoc. Am. 1989, 26, 147-151.

(3) Nakanishi, K.; Onaka, T.; Inoue, T.; Kubo, S. A New Immobilized Yeast Reactor System for Rapid Production of Beer. Proceedings of the European Brewing Convention Congress, Helsinki; IRL Press: Oxford, 1985; pp 331-338.

(4) Lommi, H. Immobilized Yeast for Maturation and AlcoholFree Beer. Brew. Distill. Int. 1990, 21, 22-23.

(5) Kunze, W. Technology Brewing and Malting; VLB: Berlin, 1996.

(6) Grönqvist, A.; Pajunen, E.; Ranta, B. Secondary Fermentation with Immobilized Yeast-Industrial Scale. Proceedings of the European Brewing Convention Congress, Zurich; IRL Press: Oxford, 1989; pp 339-346.

(7) Van De Winkel, L.; Van Beveren, P. C.; Borremans, E.; Goossens, E.; Masschelein, C. A. High Performance Immobilized Yeast Reactor Design for Continuous Beer Fermentation. Proceedings of the European Brewing Convention Congress, Oslo; IRL Press: Oxford, 1993; pp 307-314.

(8) Inoue, T. Development of a Two-stage Immobilized Yeast Fermentation System for Continuous Beer Brewing. Proceedings of the European Brewing Convention Congress, Brussels; IRL Press: Oxford, 1995; pp 25-36.

(9) Dömény, Z.; Šmogrovičová, D.; Gemeiner, P.; Šturdík, E.; Pátková, J.; Malovíková, A.; Continuous Secondary Fermentation using Immobilised Yeast. Biotechnol. Lett. 1998, 20, 1041-1045.

(10) Tata, M.; Bower, P.; Bromberg, S.; Duncombe, D.; Fehring, J.; Lau, V.; Ryder, D.; Stassi, P. Immobilized Yeast Bioreactor Systems for Continuous Beer Fermentation. Biotechnol. Prog. 1999, 15, 105-113.

(11) Brányik, T.; Vicente, A. A.; Machado Cruz, J. M.; Teixeira, J. A. Continuous Primary Beer Fermentation with Brewing Yeast Immobilized on Spent Grains. J. Inst. Brew. 2002, 108, 410-415.

(12) Mensour, N. A.; Margaritis, A.; Briens, C. L.; Pilkington, H.; Russell, I. New Developments in the Brewing Industry Using Immobilised Yeast Cell Bioreactor Systems. J. Inst. Brew. 1997, 103, 363-370.

(13) Virkajärvi, I. Feasibility of Continuous Main Fermentation of Beer Using Immobilized Yeast; Technical Research Centre of Finland VTT Publications 430: Espoo, 2001. 
(14) Virkajärvi, I.; Kronlöf, J. Long-term Stability of Immobilized Yeast Columns in Primary Fermentation. J. Am. Soc. Brew. Chem. 1998, 56, 70-75.

(15) Pajunen, E.; Grönqvist, A.; Ranta, B. Immobilized Yeast Reactor Application in Continuous Secondary Fermentation in Industrial Scale Operation. Proceedings of the European Brewing Convention Congress, Lisbon; IRL Press: Oxford, 1991; pp 361-368.

(16) Beubler, A.; Bosewitz, G.; Dobler, H.; Hantze, G.; Reins, H. J.; Sieber, J. Continuous Manufacture of Beer Wort. British Patent 1321009, 1973.

(17) Versteegh, C. H. A Process for the Continuous Preparation of Wort. European Patent 0563283, 1993

(18) Harmegnies, F.; Bonacchelli, B.; Tigel, R. Continuous Brewing. Proceedings of the European Brewing Convention Congress, Dublin; IRL Press: Oxford, 2003; pp 368-375.

(19) Nakanishi, K.; Murayama, H.; Nagara, A.; Mitsui, S. Beer Brewing Using an Immobilized Yeast Bioreactor System. Bioprocess Technol. 1993, 16, 275-289.

(20) Junter, G. A.; Coquet, L.; Vilain, S.; Jouenne, T. Immobilized-cell Physiology: Current Data and the Potentialities of Proteomics. Enzyme Microb. Technol. 2002, 31, 201212.

(21) Jones, M.; Pierce, J. S. Absorption of Amino Acids from Wort by Yeasts. J. Inst. Brew. 1964, 70, 307-315.

(22) Masschelein, C. A.; Andries, M. Future Scenario of Immobilized Systems: Promises and Limitations. European Brewery Convention Monograph XXIV. EBC Symposium Immobilized Yeast Application in the Brewing Industry, Espoo, Finland; Verlag Hans Carl Getränke-Fachverlag: Nürnberg, 1995; pp 223-238.

(23) Yamauchi, Y.; Okamoto, T.; Murayama, H.; Nagara, A.; Kashihara, T.; Nakanishi, K. Beer Brewing Using an Immobilized Yeast Bioreactor Design of an Immobilized Yeast Bioreactor for Rapid Beer Brewing System. J. Ferment. Bioeng. 1994, 78, 443-449.

(24) Šmogrovičová, D.; Dömény, Z. Beer Volatile By-product Formation at Different Fermentation Temperature Using Immobilized Yeast. Process Biochem. 1999, 34, 785-794.

(25) Pilkington, P. H.; Margaritis, A.; Mensour, N. A.; Russel, I. Fundamentals of Immobilized Yeast Cells for Continuous Beer Fermentation: A Review. J. Inst. Brew. 1998, 104, 1931.

(26) Galazzo, J. L.; Bailey, J. E. Growing Saccharomyces cerevisiae In Calcium-Alginate Beads Induces Cell Alterations which Accelerate Glucose Conversion to Ethanol. Biotechnol. Bioeng. 1990, 36, 417-426.

(27) Taipa, M. A.; Cabral, J. M. S.; Santos, H. Comparison of Glucose Fermentation by Suspended and Gel-entrapped Yeast Cells: An In Vivo Nuclear Magnetic Resonance Study. Biotechnol. Bioeng. 1993, 41, 647-653.

(28) Norton, S.; D'Amore, T. Physiological Effects of Yeast Immobilization: Application for Brewing. Enzyme Microb. Technol. 1994, 16, 365-375.

(29) Brányik, T.; Vicente, A. A.; Machado Cruz, J. M.; Teixeira, J. A. Continuous Primary Fermentation of Beer with Yeast Immobilized on Spent Grains-The Effect of Operational Conditions. J. Am. Soc. Brew. Chem. 2004, 62, 29-34.

(30) Mattiasson, B.; Hahn-Hägerdal, B. Microenvironmental Effects on Metabolic Behaviour of Immobilized Cells-A Hypothesis. Eur. J. Appl. Microbiol. Biotechnol. 1982, 16, 5255 .

(31) Monsan, P.; Durand, G.; Navarro, J. M. Immobilization of Microbial Cells by Absorption to Solid Supports. Methods Enzymol. 1987, 135, 307-318.

(32) Hilge-Rotmann, B.; Rehm, H. J. Relationship between Fermentation Capability and Fatty Acid Composition of Free and Immobilized Saccharomyces cerevisiae. Appl. Microbiol. Biotechnol. 1991, 34, 502-508.

(33) Shindo, S.; Sahara, H.; Koshino, S. Supression of $\alpha$-Acetolactate Formation in Brewing with Immobilized Yeast. J. Inst. Brew. 1994, 100, 69-72.

(34) Van Iersel, M. F. M.; Brouwer-Post, E.; Rombouts, F. M.; Abee, T. Influence of Yeast Immobilization on Fermentation and Aldehyde Reduction During the Production of AlcoholFree Beer. Enzyme Microb. Technol. 2000, 26, 602-607.
(35) Prakasham, R. S.; Kuriakose, B.; Ramakrishna, S. V. The Influence of Inert Solids on Ethanol Production by Saccharomyces cerevisiae. Appl. Biochem. Biotechnol. 1999, 82, 127134.

(36) Shen, H. Y.; Moonjai, N.; Verstrepen, K. J.; Delvaux, F. R. Impact of Attachment Immobilization on Yeast Physiology and Fermentation Performance. J. Am. Soc. Brew. Chem. 2003, 61, 79-87.

(37) Jiang, Q.; Yao, S.; Mei, L. Tolerance of Immobilized Baker's Yeast in Organic Solvents. Enzyme Microb. Technol. 2002, $30,721-725$.

(38) Hallsworth, J. E. Ethanol-induced Water Stress in Yeast. J. Ferment. Bioeng. 1998, 85, 125-137.

(39) Virkajärvi, I.; Vainikka, M.; Virtanen, H.; Home, S. Productivity of Immobilized Yeast Reactors with Very-highgravity Worts. J. Am. Soc. Brew. Chem. 2002, 60, 188-197.

(40) Jirků, V. Whole Cell Immobilization as a Means of Enhancing Ethanol Tolerance. J. Ind. Microbiol. Biotechnol. 1999, 22, 147-151.

(41) Norton, S.; Watson, K.; D'Amore, T. Ethanol Tolerance of Immobilized Brewers' Yeast Cells. Appl. Microbiol. Biotechnol. 1995, 43, 18-24.

(42) Doran, P.; Bailey, J. E. Effects of Immobilization on Growth, Fermentation Properties, and Macromolecular Properties of Saccharomyces cerevisiae Attached to Gelatin. Biotechnol. Bioeng. 1986, 28, 73-87.

(43) Jirků, V. Covalent Immobilization as a Stimulus of Cell Wall Composition Changes. Experientia 1995, 51, 569-571.

(44) Parascandola, P.; De Alteriis, E.; Sentandreu, R.; Zueco, J. Immobilization and Ethanol Stress Induce the Same Molecular Response at The Level of the Cell Wall in Growing Yeast. FEMS Microbiol. Lett. 1997, 150, 121-126.

(45) Vidgren, V.; Virkajärvi, I.; Ruohonen, L.; Salusjärvi, L.; Londensborough, J. The Free and Carrier-Bound Yeast Population from a Two-stage Immobilized Yeast Reactor are in Different Physiological Conditions. Proceedings of the European Brewing Convention Congress, Dublin; IRL Press: Oxford, 2003; pp 609-617.

(46) Mishra, P.; Prasad, R. Alterations in Fatty Acil Composition Can Selectively Affect Amino Acid Transport in Saccharomyces cerevisiae. Biochem. Int. 1987, 15, 499-508.

(47) Powell, C. D.; van Zandycke, S. M.; Quain, D. E.; Smart, K. A. Replicative Ageing and Scenescence in Saccharomyces cerevisiae and the Impact on Brewing Fermentation. Microbiology 2000, 146, 1023-1034.

(48) Barker, M. G.; Smart, K. A. Morphological Changes Associated with the Cellular Aging of a Brewing Yeast Strain J. Am. Soc. Brew. Chem. 1996, 54, 121-126.

(49) Motizuki, M.; Tsurugi, K. The Effect of Aging on Protein Synthesis in the Yeast Saccharomyces cerevisiae. Mech. Ageing Dev. 1992, 64, 235-245.

(50) Jazwinski, S. M. Aging and Senescence of the Budding Yeast Saccharomyces cerevisiae. Mol. Microbiol. 1990, 4, 337343.

(51) Maskell, D. L.; Kennedy, A. I.; Hodgson, J. A.; Smart, K. A. Chronological and Replicative Lifespan of Polyploidy Saccharomyces cerevisiae (syn. S. pastorianus). FEMS Yeast Res. 2003, 3, 201-209.

(52) Soares, E. V.; Mota, M. Flocculation Onset, Growth Phase and Genealogical Age in Saccharomyces cerevisiae. Can. J. Microbiol. 1996, 42, 539-547.

(53) Powell, C. D.; Quain, D. E.; Smart, K. A. The Impact of Brewing Yeast Cell Age on Fermentation Performance, Attenuation and Flocculation. FEMS Yeast Res. 2003, 3, 149157

(54) Deans, K.; Pinder, A.; Catley, B. J.; Hodgson, J. A. Effects of Cone Cropping and Serial Re-Pitching on the Distribution of Cell Ages in Brewery Yeast. Proceedings of the European Brewing Convention Congress, Maastricht; IRL Press: Oxford, 1997; pp 469-476.

(55) Jenkins, C.; Kennedy, A.; Thurston, P.; Hodgson, J.; Smart, K. Impact of Wort Composition and Serial Repitching on Lager Brewing Yeast Fermentation Performance and Organelle Integrity. Proceedings of the European Brewing Convention Congress, Budapest; IRL Press: Oxford, 2001; pp 378-387. 
(56) Kronlöf, J.; Härkönen, T.; Hartwall, P.; Home, S.; Linko, M. Main Fermentation with Immobilized Yeast. Proceedings of the European Brewing Convention Congress, Zurich; IRL Press: Oxford, 1989; pp 355-362.

(57) Pilkington, H.; Margaritis, A.; Mensour, N.; Sobczak, J.; Hancock, I.; Russel, I. Kappa-Carrageenan Gel Immobilization of Lager Brewing Yeast. J. Inst. Brew. 1999, 105, 398404.

(58) Brányik, T.; Vicente, A.; Kuncová, G.; Podrazký, O.; Dostálek, P.; Teixeira, J. Growth Model and Metabolic Activity of Brewing Yeast Biofilm on the Surface of Spent Grains: A Biocatalyst for Continuous Beer Fermentation. Biotechnol. Prog. 2004, 20, 1733-1740.

(59) Ryder, D. S.; Masschelein, C. A. The Growth Process of Brewing Yeast and the Biotechnological Challenge. J. Am. Soc. Brew. Chem. 1985, 43, 66-75.

(60) Inoue, T. Immobilized Cell Technology-A New Possibility for Brewing? J. Am. Soc. Brew. Chem. 1988, 46, 64-66.

(61) Meilgaard, M. C. Flavor Chemistry of Beer. II. Flavor and Threshold of 239 Aroma Volatiles. Tech. Q.-Master Brew. Assoc. Am. 1975, 12, 151-168.

(62) Pugh, T. A.; Maurer, J. M.; Pringle, A. T. The Impact of Wort Nitrogen Limitation on Yeast Fermentation Performance and Diacetyl. Tech. Q.-Master Brew. Assoc. Am. 1997, $34,185-189$

(63) García, A. I.; García, L. A. Días M. Modelling of Diacetyl Production During Beer Fermentation. J. Inst. Brew. 1994, 100, 179-183.

(64) Šmogrovičová, D.; Dömény, Z.; Švitel, J. Effect of Immobilized Cell Concentration on Beer Quality in Continuous Fermentation. Food Biotechnol. 1998, 1/2, 123-137.

(65) Godtfredsen, S. E.; Rasmussen, A. M.; Ottesen, M.; Rafn, P.; Peitersen, N. Occurrence of $\alpha$-acetolactate Decarboxylases Among Lactic-acid Bacteria and their Utilization for Maturation of Beer. Appl. Microbiol. Biotechnol. 1984, 20, 23-28.

(66) Kronlöf, J.; Linko, M. Production of Beer Using Immobilized Yeast Encoding $\alpha$-acetolactate Decarboxylase. J. Inst. Brew. 1992, 98, 479-491.

(67) Yamano, S.; Tomizuka, K.; Sone, H.; Imura, M.; Takeuchi, T.; Tanaka, J.; Inoue, T. Brewing Performance of a Brewer's Yeast Having $\alpha$-Acetolactate Decarboxylase from Acetobacter aceti Subsp. xylinum. J. Biotechnol. 1995, 39, 21-26.

(68) Dillemans, M.; Goosens, E.; Goffin, O.; Masschelein, C. A. The Amplification Effect of the ILV5 Gene on the Production of Vicinal Diketones in Saccharomyces cerevisiae. J. Am. Soc. Brew. Chem. 1987, 45, 81-84.

(69) Pajunen, E. Immobilized Lager Beer Maturation: DEAECellulose at Sinebrychoff. European Brewery Convention Monograph XXIV. EBC Symposium Immobilized Yeast Application in the Brewing Industry, Espoo, Finland; Verlag Hans Carl Getränke-Fachverlag: Nürnberg, 1995; pp 2440.

(70) Yamauchi, Y.; Okamoto, T.; Murayama, H.; Kajino, K.; Amikura, T.; Hiratsu, H.; Nagara, A.; Kamiya, T.; Inoue, T. Rapid Maturation of Beer Using an Immobilized Yeast Bioreactor. 1. Heat Conversion of $\alpha$-acetolactate. J. Biotechnol. 1995, 38, 101-108.

(71) Linko, M.; Kronlöf, J. Main Fermentation with Immobilized Yeast. Proceedings of the European Brewing Convention Congress, Lisbon; IRL Press: Oxford, 1991; pp 353-360.

(72) Masschelein, C. A. A Realistic View on the Role of Research in the Brewing Industry Today. J. Inst. Brew. 1997, 103, 103113.

(73) Okabe, M.; Katoh, M.; Furugoori, F.; Yoshida, M.; Mitsui, S. Growth and Fermentation Characteristics of Bottom Brewer's Yeast under Mechanical Stirring. J. Ferment. Bioeng. 1992, 73, 148-152.

(74) Oshita, K.; Kubota, M.; Uchida, M.; Ono, M. Clarification of the Relationship Between Fusel Alcohol Formation and Amino Acid Assimilation by Brewing Yeast Using ${ }^{13} \mathrm{C}$-Labeled Amino Acid. Proceedings of the European Brewing Convention Congress, Brussels; IRL Press: Oxford, 1995; pp 387-394.

(75) Romano, P.; Suzzi, G. Origin and Production of Acetoin During Wine Yeast Fermentation. Appl. Environ. Microbiol. 1996, 62, 309-315.
(76) Van Iersel, M. F. M.; Van Dieren, B.; Rombouts, F. M.; Abee, T. Flavor Formation and Cell Physiology during the Production of Alcohol-free Beer with Immobilized Saccharomyces cerevisiae. Enzyme Microb. Technol. 1999, 24, 407411.

(77) Masschelein, C. A.; Carlier, A.; Ramos-Jeunehomme, C.; Abe, I. The Effect of Immobilization on Yeast Physiology and Beer Quality in Continuous and Discontinuous Systems. Proceedings of the European Brewing Convention Congress, Helsinki; IRL Press: Oxford, 1985; pp 339-346.

(78) Debourgh, A.; Laurent, M.; Verlinden, V.; Van Winkel, L.; Masschelein, C. A.; Van Nedervelde, L. Yeast Physiological State on Carbonyl Reduction. European Brewery Convention Monograph XXIV; EBC Symposium Immobilized Yeast Application in the Brewing Industry, Espoo, Finland; Verlag Hans Carl Getränke-Fachverlag: Nürnberg, 1995; pp 158174.

(79) Virkajärvi, I. Profiting from Immobilized Fermentation. Proceedings of the Fifth Aviemore Conference on Malting, Brewing and Distilling; Institute of Brewing: London, 1999; pp 290-293.

(80) Virkajärvi, I.; Lindborg, K.; Kronlöf, J.; Pajunen, E. Effects of Aeration on Flavor Compounds in Immobilized Primary Fermentation. Monatsschr. Brauwiss. 1999, 52, 9-12; 2528.

(81) Virkajärvi, I.; Pohjala, N. Primary Fermentation with Immobilized Yeast: Some Effects of Carrier Materials on the Flavour of the Beer. J. Inst. Brew. 2000, 106, 311-318.

(82) Linko, M.; Virkajärvi, I.; Pohjala, N.; Lindborg, K.; Kronlöf, J.; Pajunen, E. Main Fermentation with Immobilized Yeast-A Breakthrough? Proceedings of the European Brewing Convention Congress, Maastricht; IRL Press: Oxford, 1997; pp 385394.

(83) Brányik, T.; Vicente, A. A.; Machado Cruz, J. M.; Teixeira, J. A. Spent Grains-A New Support for Brewing Yeast Immobilization. Biotechnol. Lett. 2001, 23, 1073-1078.

(84) Breitenbücher, K.; Mistler, M. Fluidized Bed Fermenters for the Continuous Production of Non-Alcoholic Beer with Open-Pore Sintered Glass Carriers. European Brewery Convention Monograph XXIV. EBC Symposium Immobilized Yeast Application in the Brewing Industry, Espoo, Finland; Verlag Hans Carl Getränke-Fachverlag: Nürnberg, 1995; pp 77-89.

(85) Cashin, M. M. Comparative Studies of Five Porous Supports for Yeast Immobilization by Adsorption/Attachment. $J$. Inst. Brew. 1996, 102, 5-10.

(86) Van Iersel, M. F. M.; Meersman, E.; Arntz, M.; Rombouts, F. M.; Abee, T. Effect of Environmental Conditions on Flocculation and Immobilisation of Brewer's Yeast During Production of Alcohol-Free Beer. J. Inst. Brew. 1998, 104, 131-136.

(87) Brányik, T.; Vicente, A.; Oliveira, R.; Teixeira, J. PhysicoChemical Surface Properties of Brewing Yeast Influencing their Immobilization to Spent Grains in a Continuous BubbleColumn Reactor. Biotechnol. Bioeng. 2004, 88, 84-93.

(88) Michaud, S.; Bernet, N.; Roustan, M.; Delgenes, J. P. Influence of Hydrodynamic Conditions on Biofilm Behaviour in a Methanogenic Inverse Turbulent Bed Reactor. Biotechnol. Prog. 2003, 19, 858-863.

(89) Willaert, R. G.; Baron, G. V. Gel Entrapment and MicroEncapsulation: Methods, Applications and Engineering Principles. Rev. Chem. Eng. 1996, 12, 5-205.

(90) Yamauchi, Y.; Kashihara, T.; Murayama, H.; Nagara, A.; Okamoto, T.; Mawatari, M. Scale-up of Immobilized Yeast Bioreactor for Continuous Fermentation of Beer. Tech. Q.Master Brew. Assoc. Am. 1994, 31, 90-94.

(91) Ryder, D. S.; Masschelein, C. A. Immobilized Yeast in Brewing-A Current Perspective. Proceedings of the European Brewing Convention Congress, Lisbon; IRL Press: Oxford, 1991; pp 345-352.

(92) Willaert, R. Beer Production Using Immobilized Cell Technology. Minerva Biotecnol. 2000, 12, 319-330.

(93) Karel, S. F.; Libicki, S. B.; Robertson, C. R. The Immobilization of Whole Cells: Engineering Principles. Chem. Eng. Sci. 1985, 40, 1321-1354. 
(94) Geiger, K. H.; Compton, J. Continuous Fermentation Process. Canadian Patent 545,867, 1957.

(95) Coutts, M. W. Process for the Manufacture of Beer, Ale and the Like. United States Patent 3,234,026, 1966.

(96) Mafra, I.; Machado Cruz, J. M.; Teixeira, J. A. Beer Maturation in a Continuously Operating Bioreactor Using a Flocculating Brewer's Yeast Strain. Proceedings of the European Brewing Convention Congress, Maastricht; IRL Press: Oxford, 1997; pp 509-516.

(97) Verstrepen, K. J.; Derdelinckx, G.; Verachtert, H.; Delvaux, F. R. Yeast Flocculation: What Brewers Should Know. Appl. Microbiol. Biotechnol. 2003, 61, 197-205.

(98) Baker, D. A.; Kirsop, B. H. Rapid Beer Production and Conditioning Using a Plug Fermenter. J. Inst. Brew. 1973 , $79,487-494$

(99) Livingston, A. G.; Zhang, S. F. Hydrodynamic Behaviour of Three-Phase (Gas-Liquid-Solid) Airlift Reactors. Chem. Eng. Sci. 1993, 48, 1641-1654.

(100) Chisti, Y. Airlift Bioreactors; Elsevier Applied Science: London, 1989.

(101) Pollard, D. J.; Shamlow, P. A.; Lilly, M. D.; Ison, A. P. Saccharomyces cerevisiae Fermentation In A Pilot Scale Airlift Bioreactor: Comparison Of Air Sparger Configuration. Bioprocess Eng. 1996, 15, 279-288.

(102) Vicente, A. A.; Teixeira, J. A. Hydrodynamic Performance of a Three-phase Airlift Bioreactor with an Enlarged Degassing Zone. Bioprocess Eng. 1995, 14, 17-22.

(103) Lu, W. J.; Hwang, S. J.; Chang, C. M. Liquid Velocity and Gas Holdup in Three-phase Internal Loop Airlift Reactors with Low-Density Particles. Chem. Eng. Sci. 1995, 50, 13011310.

(104) Klein, J.; Vicente, A. A.; Teixeira, J. A. Hydrodynamics of a Three-phase Airlift Reactor with an Enlarged SeparatorApplication to High Cell Density Systems. Can. J. Chem. Eng. 2003, 81, 1-11.

(105) Siegel, M.; Merchuk, J. C. Hydrodynamics in Rectangular Airlift Reactors: Scale-up and the Influence of Gas-liquid Separator Design. Can. J. Chem. Eng. 1991, 69, 465-473.

(106) Russel, A. B.; Thomas, C. R.; Lilly, M. D. The Influence of the Vessel Height and Top-Section Size on the Hydrodynamic Characteristics of Airlift Fermentors. Biotechnol. Bioeng. 1994, 43, 69-76.

(107) Choi, K. H.; Chisti, Y.; Moo-Young, M. Influence of the Gas-Liquid Separator Design on Hydrodynamic and Mass Transfer Performance of Split-channel Airlift Reactors. $J$. Chem. Technol. Biotechnol. 1995, 62, 327-332.

(108) Cai, J.; Nieuwstad, T. J.; Kop, J. H. Fluidization and Sedimentation of Carrier Material in a Pilot-scale Airlift Internal-loop Reactor. Water Sci. Technol. 1992, 26, 24812484.

(109) Merchuk, J. C.; Ladwa, N.; Cameron, A.; Bulmer, M.; Pickett, A. Concentric-tube Airlift Reactors: Effects of Geometrical Design on Performance. AIChE J. 1994, 40, 11051117.

(110) Ganzeveld, K. J.; Chisty, Y.; Moo-Young, M. Hydrodynamic Behaviour of Animal Cell Microcarrier Suspensions in Split-cylinder Airlift Bioreactors. Bioprocess Eng. 1995, 12 , 239-247.

(111) Klein, J.; Maia, J.; Vicente, A. A.; Domingues, L.; Teixeira, J. A.; Jurascík, M. Relationships Between Hydrodynamics and Rheology of Flocculating Yeast Suspensions in a HighCell-Density Airlift Bioreactor. Biotechnol. Bioeng. 2005, 89, 393-399.

(112) Freitas, C.; Teixeira, J. A. Hydrodynamic Studies in an Airlift Reactor with an Enlarged Degassing Zone. Bioprocess Eng. 1998, 18, 267-279.

(113) Freitas, C.; Teixeira, J. A. Effect of Liquid-phase Surface Tension on Hydrodynamics of a Three-phase airlift Reactor with an Enlarged Degassing Zone. Bioprocess Eng. 1998, 19, 451-457.

(114) Gluz, M. D.; Merchuk, J. C. Modified Airlift Reactors: The Helical Flow Promoters. Chem. Eng. Sci. 1996, 51, 29152920.

(115) Schlotelburg, C.; Gluz, M.; Popovic, M.; Merchuk, J. C. Characterization of an Airlift Reactor with Helical Flow Promoters. Can. J. Chem. Eng. 1999, 77, 804-810.
(116) Vicente, A. A.; Dluhý, M.; Teixeira, J. A. Increase of Ethanol Productivity in an Airlift Reactor with a Modified Draught Tube. Can. J. Chem. Eng. 1999, 77, 497-502.

(117) Pajunen, E. The Behaviour of Immobilized Yeast Cells. Cerevisiae 1996, 4, 33-37.

(118) Dufour, J. P.; Verstrepen, K.; Derderlinckx, G. Continuous Fermentation Systems. In Yeasts in Food; Boekhout, T., Robert, V., Eds.; Woodhead Publishing Limited: Cambridge, 2003; pp 376-377.

(119) McMurrough, I. Scope and Limitations for Immobilized Cell Systems in the Brewing Industry. European Brewery Convention Monograph XXIV. EBC Symposium Immobilized Yeast Application in the Brewing Industry, Espoo, Finland; Verlag Hans Carl Getränke-Fachverlag: Nürnberg, 1995; pp $2-16$.

(120) Kronlöf, J.; Haikara, A. Contamination of Immobilized Yeast Bioreactors. J. Inst. Brew. 1991, 97, 375-380.

(121) Haikara, A.; Kronlöf, J. Hygiene and Microbiological Control Requirements of Immobilized System. European Brewery Convention Monograph XXIV. EBC Symposium Immobilized Yeast Application in the Brewing Industry, Espoo, Finland; Verlag Hans Carl Getränke-Fachverlag: Nürnberg, 1995; pp 194-206.

(122) Haikara, A.; Virkajärvi, I.; Kronlöf, J.; Pajunen, E. Microbiological Contamination in Immobilized Yeast Bioreactors for Primary Fermentation. Proceedings of the European Brewing Convention Congress, Maastrichtl IRL Press: Oxford, 1997; pp 439-446.

(123) Chisti, Y. Build Better Industrial Bioreactors. Chem. Eng. Prog. 1992, 88, 55-58.

(124) Mensour, N. A.; Margaritis, A.; Briens, C. L.; Pilkington, H.; Russel, I. Application of Immobilized Yeast Cells in the Brewing Industry. In Immobilized Cells: Basics and Applications; Wijffels, R. H., Buitelaar, R. M., Bucke, C., Tramper, J., Eds.; Elsevier Science: Amsterdam, 1996; pp 661-671.

(125) Andries, M.; van Beveren, P. C.; Goffin, O.; Rajotte, P.; Masschelein, C. A. Practical Results Using the Meura-Delta Immobilized Yeast Fermentation System. Brewers' Guardian 1997, 26-28.

(126) Van Iersel, M. F. M.; Meersman, E.; Swinkels, W.; Abee, T.; Rombouts, F. M. Continuous Production of Non-alcohol Beer by Immobilized Yeast at Low Temperature. J. Ind. Microbiol. 1995, 14, 495-501.

(127) Van Dieren, B. Yeast Metabolism and the Production of Alcohol-free Beer. European Brewery Convention Monograph XXIV. EBC Symposium Immobilized Yeast Application in the Brewing Industry, Espoo, Finland; Verlag Hans Carl Getränke-Fachverlag: Nürnberg, 1995; pp 66-76.

(128) Linko, M.; Haikara, A.; Ritala, A.; Penttilä, M. Recent Advances in the Malting and Brewing Industry. J. Biotechnol. 1998, 65, 85-98.

(129) Andries, M.; van Beveren, P. C.; Goffin, O.; Masschelein, C. A. Design of a Multi-purpose Immobilized Yeast Bioreactor System for Application in the Brewing Process. European Brewery Convention Monograph XXIV. EBC Symposium Immobilized Yeast Application in the Brewing Industry, Espoo, Finland; Verlag Hans Carl Getränke-Fachverlag: Nürnberg, 1995; pp 134-143.

(130) Šmogrovičová, D.; Dömény, Z.; Slugeň, D.; Pátková, J.; Bafrncová, P. Gluten Pellets to Immobilize Yeast for Brewery Fermentations. Monatsschr. Brauwiss. 1999, 7/8, 119122 .

(131) Cop, J.; Dyon, D.; Iserentant, D.; Masschelein, C. A. Reactor Design Optimization with a View to the Improvement of Amino Acid Utilization and Flavour Development of Calcium Alginate Entrapped Brewing Yeast Fermentations. Proceedings of the European Brewing Convention Congress, Zurich; IRL Press: Oxford, 1989; pp 315-322.

Accepted for publication March 10, 2005 